\title{
Laser plasma x-ray contact microscopy of living specimens using a chemically amplified epoxy resist
}

\author{
A. C. Cefalas a) \\ National Hellenic Research Foundation, TPCI, Athens 11635, Greece \\ P. Argitis \\ Institute of Microelectronics, NCSR “DEMOKRITOS," 15310 Ag. Paraskevi, Greece \\ Z. Kollia \\ National Hellenic Research Foundation, TPCI, Athens 11635, Greece \\ E. Sarantopoulou \\ Physics Department, National Technical University of Athens, Zografou, Athens, Greece
}

T. W. Ford, A. D. Stead, and A. Marranca

School of Biological Sciences, Royal Holloway, University of London, Egham, Surrey TW20 OEX, United Kingdom

C. N. Danson, J. Knott, and D. Neely

Central Laser Facility, Rutherford Appleton Laboratory, Chilton, Didcot, Oxon OX11 OQX, United Kingdom

(Received 24 November 1997; accepted for publication 17 April 1998)

\begin{abstract}
We report on the use of an epoxy based chemically amplified resist, to produce x-ray images of living biological specimens, exposed with laser plasma generated soft $\mathrm{x}$ rays, in the water window $(2.3-4.4 \mathrm{~nm})$. The photoresist response was at least two orders of magnitude "faster" than polymethyl methacrylate, the standard resist used so far in soft x-ray contact microscopy. Atomic force and scanning electron microscopy of the biological specimen images, recorded in the resist, clearly showed the flagella of the motile green alga, chlamydomonas, suggesting a lateral resolution better than $150 \mathrm{~nm}$. The resist was also capable of providing height features, as small as $20 \mathrm{~nm}$, in atomic force microscope depth profiles and discriminating the flagella intersection areas. (C) 1998 American Institute of Physics. [S0003-6951(98)00225-3]
\end{abstract}

Soft x-ray contact microscopy (SXCM), is an interdisciplinary technique that has many applications in both life and material sciences. In the case of life sciences, SXCM enables the study of the ultrastructure of living hydrated specimens, without the need of dehydration or other chemical pretreatment, by using suitable pulsed $\mathrm{x}$-ray sources such as laser plasmas. ${ }^{1-4}$ The interest in using soft $\mathrm{x}$ rays, in the so called "water window" (2.3-4.4 $\mathrm{nm}$ or $280-530 \mathrm{eV})$, is based on the low attenuation at these wavelengths caused by water, as compared to the attenuation caused by organic matter. Indeed, just below the oxygen $K$ edge $(2.4 \mathrm{~nm}), 1 \mu \mathrm{m}$ water has only $20 \%$ absorption, while the carbon containing proteins have distinctively higher absorbance. ${ }^{5}$ Therefore, good contrast masking of the incident radiation is provided. The successful imaging of a biological specimen requires the development of sensitive photoresist materials for image recording; these should have capabilities of high resolution lithography and an extended grayscale. Up to now, the only known photoresist used successfully in SXCM has been polymethyl methacrylate (PMMA) ${ }^{6-8}$ This is a high resolution photoresist when exposed to $e$-beam or x-ray radiation, with contrast suitable for grayscale recording; nevertheless, it is a relatively slow photoresist (Ralph Feder and co-workers at IBM also used a copolymer of PMMA with MMA with about a twofold increase in sensitivity ${ }^{7}$ ) and, therefore, re-

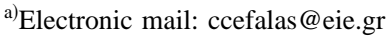

quires a very large fluence of $\mathrm{x}$ rays for imaging. This fact has limited the range of $\mathrm{x}$-ray sources that can be used mainly to those of large national facilities.

Laser plasma sources are devices that can efficiently generate $\mathrm{x}$ rays. The intensity and the spectral distribution of the $\mathrm{x}$-ray emission from the plasma depends on many parameters, such as the energy of the laser pulse, its wavelength, its pulse duration, the focusing of the beam on the target and the atomic number of the target. The work reported in this letter was carried out using the Vulcan Nd:glass laser facility at the Rutherford Appleton Laboratory, UK, whose rod chain output can deliver $11 \mathrm{~J}$ at $1064 \mathrm{~nm}$. This can be delivered on a 2 min shot cycle to a stand alone target area where it was focused on a yttrium target as an x-ray source. A very sensitive $e$-beam photoresist, used for the first time in SXCM, enabled the biological imaging with the specific source in single pulse experiments in the water window spectral range. This photoresist is an epoxy novolac based chemically amplified resist EPR which is developed for fast $e$-beam microlithography ${ }^{9,10}$ and it has been proven capable of resolving sub tenth micron features.

The experimental apparatus for producing soft $\mathrm{x}$-ray contact images, consisted of the laser source and the vacuum chamber. The target arrangement containing the biological sample and the photoresist has been described elsewhere. ${ }^{11}$ The vacuum chamber was evacuated at a pressure of $10^{-5}$ mbar and the laser beam was focused with a lens of 40 $\mathrm{cm}$ focal length on a planar yttrium foil target. The produced $\mathrm{x}$ rays were monitored with a pin photodiode and an $\mathrm{x}$-ray 


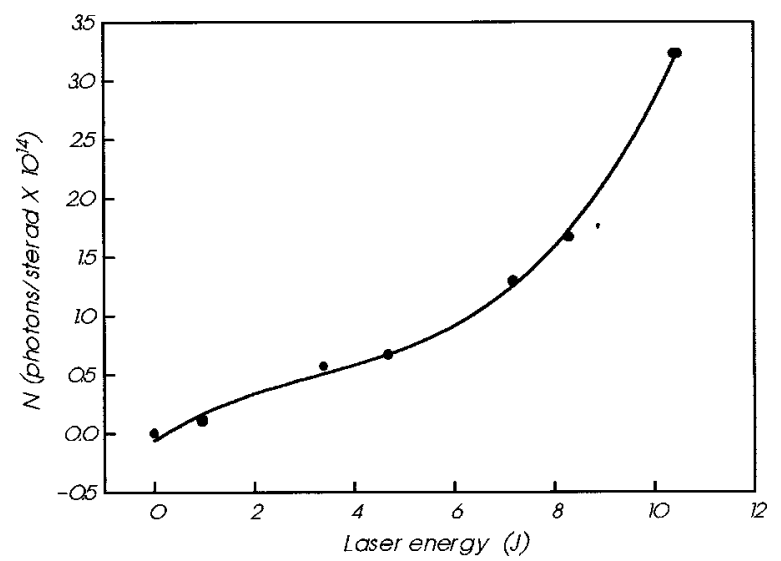

FIG. 1. Number of $x$-ray water window photons per sterad as a function of the laser energy focused on the yttrium target.

diode array. From Fig. 1, which indicates the number of $\mathrm{x}$-ray photons in the water window per sterad as a function of the energy of the laser pulse, and taking into consideration the geometry of the experiment, we estimate the fluence of $\mathrm{x}$-ray photons in the water window incident on the aluminum foil, which is placed in front of the $\mathrm{Si}_{3} \mathrm{~N}_{4}$ window (0.5 $\times 0.5 \mathrm{~mm}$ ) of the sample holder. This fluence is for instance $4 \mathrm{~mJ} / \mathrm{cm}^{2}$, at $6 \mathrm{~J}$ of laser energy at an average $\mathrm{x}$-ray photon energy of $405 \mathrm{eV}$. The absorption coefficient of the $\mathrm{Al}$ foil and the $\mathrm{Si}_{3} \mathrm{~N}_{4}$ window is $\sim 2 \times 10^{4} \mathrm{~cm}^{-1}$ in the water window. ${ }^{3,4}$ Therefore, we estimate that for an $\mathrm{Al}$ foil and a $\mathrm{Si}_{3} \mathrm{~N}_{4}$ window $0.1 \mu \mathrm{m}$ thick, the fluence of $\mathrm{x}$ rays in the water window, incident on the sample, is $2.5 \mathrm{~mJ} / \mathrm{cm}^{2}$ at $6 \mathrm{~J}$ of laser energy and $68 \mu \mathrm{J} / \mathrm{cm}^{2}$ at $300 \mathrm{~mJ}$ of laser energy focused on the yttrium target, respectively.

Initial experiments to compare the sensitivity of PMMA and EPR were done in the absence of a biological specimen. A Du Pont Elvacite 2041 [molecular weight (MW) 443 000] polymer was used for PMMA resist formulation. The EPR resist formulation described elsewhere, ${ }^{9}$ was used as the standard EPR. In general, in these experiments we followed the recommended conditions such as for optimum resolution reported before ${ }^{9}$ with the exception of developer, where methyl isobutyl ketone was used as giving lower contrast with respect to the standard developer. High contrast conditions such as the ones preferred in microlithography are not suitable for this application because they would give a black and white image (without gray areas) and would not allow any depth differences coming from different degrees of masking by the specimen to be recorded in the relief image. In Fig. 2 the sensitivity curve (normalized thickness vs energy of laser pulse) is given for an EPR of $480 \mathrm{~nm}$ starting thickness. A formulation made with a higher MW epoxy novolac polymer (MW 3300 vs 2250) is even more sensitive: the first image is obtained at $300 \mathrm{~mJ}$ laser pulse energy. PMMA used as a reference gave a first image of $40 \mathrm{~nm}$ depth difference between exposed and unexposed areas, as measured with a Dektak profilometer, at $4.6 \mathrm{~J}$ laser pulse energy and an image of $70 \mathrm{~nm}$ at maximum available laser pulse energy, i.e., at 10.6 $\mathrm{J}$. Thus on the basis of the calculations of $\mathrm{x}$-ray flux produced at different laser energies, the minimum flux for image production with PMMA is $2.5 \mathrm{~mJ} \mathrm{~cm}$ (in accordance with previously published figures $\mathrm{s}^{11-13}$ ) and the corresponding
bownloaded 08 Dec 2008 to 194.177 .215 .121 . Redistribution subje

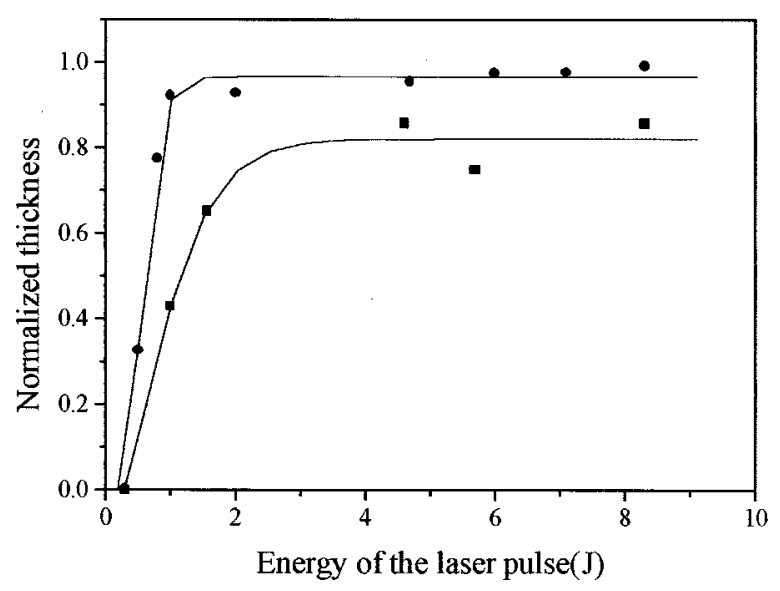

FIG. 2. Normalized thickness for the EPR photoresist as a function of the laser energy focused on the yttrium target; $(\mathbf{O})$ thickness measurement with a Dektak profilometer, ( $\square$ ) thickness measurement with AFM.

value for EPR is only $\sim 0.07 \mathrm{~mJ} \mathrm{~cm}{ }^{-2}$, giving a difference of approximately two orders of magnitude for the two materials. In comparing these lithographic results one should always keep in mind that PMMA is a positive resist whereas the EPR resist is negative. Thus the value for comparison is selected to be the threshold energy for recording atomic force microscope (AFM) (Burleigh ARIS 3300) detectable height differences. The big sensitivity difference between the two resists is expected because EPR is a chemically amplified resist. ${ }^{9}$ This difference is also in good agreement with results at shorter wavelength $\mathrm{x}$ rays reported for related $\mathrm{EPR}^{10}$ and PMMA ${ }^{7,8}$ formulations and with unpublished results with $\mathrm{ArF}$ and $\mathrm{F}_{2}$ lasers together with quadrapole mass spectrometry studies.

In biological imaging experiments the living specimens were cells of the motile green alga, chlamydomonas, which were placed in a droplet of medium. The droplet was sandwiched between a $120 \mathrm{~nm}$ thick silicon nitride window and a photoresist coated Si wafer piece and placed into the holder, assembled and tightened to ensure that the specimens were in close contact with the photoresist. The thickness of the water was monitored by light microscopy. A practical way to estimate the thickness is to adjust it to the thickness of the diameter of the cell(s) to be measured. In any case the attenuation of the radiation caused by the water layer increases the laser pulse energy requirements. To filter out the photons with energy lower than $1 \mathrm{keV}$, a thin $(0.1 \mu \mathrm{m})$ aluminum film was also placed in front of the silicon nitride window. Throughout the experiments the distance between the target and the front surface (i.e., silicon nitride window) was maintained at $15 \mathrm{~mm}$.

In the experiments with biological specimens no image (depth difference measurable with AFM) was obtained with PMMA as a recording material, even with the higher pulse energy available. On the contrary, with the EPR resist biological imaging was possible. Images of chlamydomonas cells were obtained successfully with electron and atomic force microscopy as shown in Figs. 3 and 4. The diameter of the cell body was between 1 and $5 \mu \mathrm{m}$ and the corresponding thickness of the flagella was between 150 and $300 \mathrm{~nm}$. These images clearly show the cell body and the flagella and suggest a lateral resolution considerably better than $150 \mathrm{~nm}$. The to AlP license or copyright; see http://apl.aip.org/apl/copyright.jsp 


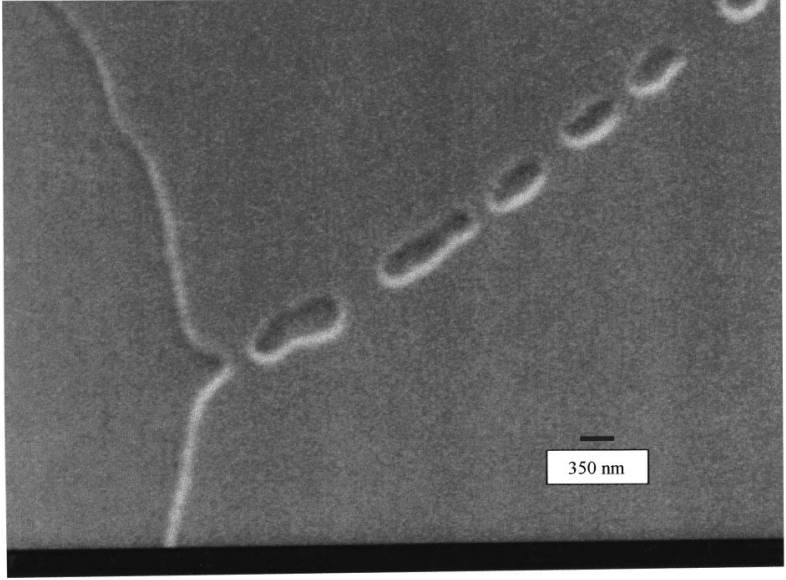

FIG. 3. Image of chlamydomonas taken with EPR photoresist. Picture was taken with a scanning electron microscope. The minimum measurable diameter of the flagellum was $150 \mathrm{~nm}$.

diameters of the flagella of small size cells are approximately $150 \mathrm{~nm}$, and these are clearly distinguishable. For successful biological imaging it is also necessary to be able to distinguish adjacent areas of the specimen, which may differ only marginally in their ability to absorb soft $\mathrm{x}$ rays. This is controlled by the contrast characteristic of the photoresist. The image of Fig. 4 shows that the absorption by the cell body was almost sufficient to result in the complete dissolution of the photoresist when it was developed. However, it was possible to differentiate between a single flagellum and areas where two flagella overlapped, (Fig. 4). In this case the photoresist area corresponding to the overlapping regions was $\sim 80 \mathrm{~nm}$ deep, whereas images of single flagella were only $\sim 20 \mathrm{~nm}$. Since the depth of the images of the cell body was $\sim 100 \mathrm{~nm}$ deep it is concluded that two flagella also absorbed sufficient $\mathrm{x}$ rays to produce a maximum response. Optimiza-

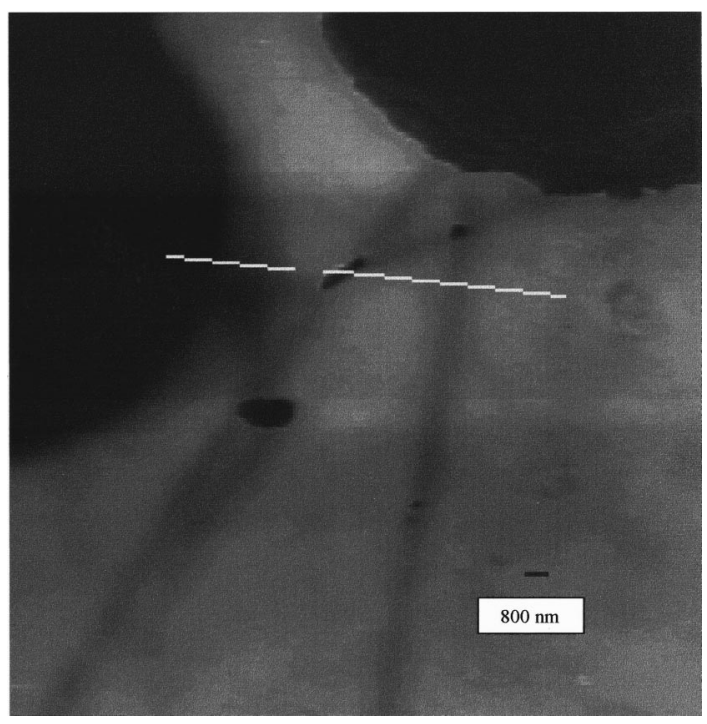

FIG. 4. Image of two chlamydomonas using the EPR photoresist. The depth of the area imaging a single flagellum is $20 \mathrm{~nm}$, where those of overlapping flagella are $80 \mathrm{~nm}$ deep. tion of the imaging conditions for a more linear relation between attenuation of radiation and resist thickness, using the same or comparable sources, is allowed by the high sensitivity of this type of resist and the tunability of its contrast. ${ }^{9}$

Using PMMA in conjunction with a similar source to specimen distance, biological imaging was not possible when the specimen was behind a $0.1 \mu \mathrm{m}$ aluminum filter even at the maximum energy pulse obtained from the laser. This suggests that in previous imaging experiments a significant contribution to image formation may have been from higher energy photons or from ultraviolet (UV) which is also filtered out by the aluminum coating used in the present experiment. $^{13}$

In conclusion, we have demonstrated that the chemically amplified photoresist EPR used in this study is two orders of magnitude more sensitive than the traditionally used PMMA in "water window" $\mathrm{x}$ rays and that such materials can be used with suitable optimization of processing conditions in biological imaging experiments. Perhaps more significantly, however, is that such photoresists could be used with less intense x-ray sources and could therefore be the basis of development of a small scale soft $\mathrm{x}$-ray microscope using a small commercial laser.

This work was carried out under the Human Capital and mobility project, Contract No. ERB CHRXCT 940600. Final support for the work at RAL for A. C. Cefalas and P. Argitis was provided through the EU Access to Large Facilities program, Contract No. ERB FMGE CT 95 0053. The authors also acknowledge stimulating discussions with Dr. M. Hatzakis and E. Tegou for help with the scanning electron microscope pictures.

${ }^{1}$ T. W. Ford, A. D. Stead, and R. A. Cotton, Electron Microsc. Rev. 4, 269 (1991).

${ }^{2}$ J. Kirz, C. Jacobsen, and M. Howells, Q. Rev. Biophys. 28, 33 (1995).

${ }^{3}$ L. Palladino, A. Reale, G. Taglieri, D. Batani, S. Bollanti, P. Di Lazzaro, F. Flora, T. Letardi, S. Schina, M. Belli, and A. Scafati, Nuovo Cimento V 5D, 1133 (1993).

${ }^{4}$ S. Bollanti, P. Di Lazzaro, F. Flora, G. Giordano, T. Letardi, G. Schina, C. E. Zheng, L. Filippi, L. Palladino, A. Reale, G. Taglieri, D. Batani, A. Mauri, M. Belli, A. Scafati, and L. Reale, J. X-Ray Sci. Technol. V5, 261 (1995).

${ }^{5}$ R. A. Cotton, J. H. Fletcher, C. E. Webb, A. D. Stead, and T. W. Ford, Proc. SPIE 2015, 86 (1994)

${ }^{6}$ R. Feder, E. Spiller, J. Topilian and M. Hatzakis, 7th International Conference of Electron and Ion Beam Science and Technology, Proceedings of the ECS (Electrochemical Society, Pennington, NJ, 1976), p. 198.

${ }^{7}$ I. Haller, R. Feder, M. Hatzakis, and E. Spiller, J. Electrochem. Soc. 126, 154 (1979).

${ }^{8}$ W. M. Moreau, Semiconductor Lithography (Plenum, New York, 1988), p. 81.

${ }^{9}$ P. Argitis, I. Raptis, C. J. Aidinis, N. Glezos, M. Baciocchi, J. Everett, and M. Hatzakis, J. Vac. Sci. Technol. B 13, 3030 (1995).

${ }^{10}$ M. Hatzakis, K. J. Stewart, J. M. Shaw, and S. A. Rishton, J. Electrochem. Soc. 138, 1076 (1991).

${ }^{11}$ A. D. Stead, T. W. Ford, C. Danson, D. Peplar, and M. Ebbage, Annual Report to the Laser Facility Committee, Rutherford Appleton Laboratory, 1995, p. 47.

${ }^{12}$ T. Tomie, H. Shimizu, T. Majima, M. Yamada, T. Kanayama, H. Kondo, M. Yano, and M. Ono, Science 252, 691 (1991).

${ }^{13}$ R. A. Cotton, A. D. Stead, T. W. Ford, J. H. Fletcher, and C. E. Webb, Proc. SPIE 1741, 204 (1993). 